\title{
Proton density fat fraction of the spinal column: an MRI cadaver study
}

\author{
Merle S. Losch ${ }^{1 *} \mathbb{0}$, Akash Swamy ${ }^{1,2}$, Adrian Elmi-Terander ${ }^{3,4}$, Erik Edström, ${ }^{3,4}$ Benno H. W. Hendriks ${ }^{1,2}$ \\ and Jenny Dankelman ${ }^{1}$
}

*Correspondence:

m.s.losch@tudelft.nl

${ }^{1}$ Department

of Biomechanical

Engineering, Delft University

of Technology, Delft, The

Netherlands

Full list of author information is available at the end of the article

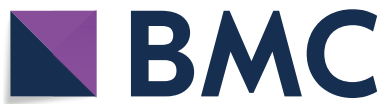

(c) The Author(s) 2021. This article is licensed under a Creative Commons Attribution 4.0 International License, which permits use, sharing, adaptation, distribution and reproduction in any medium or format, as long as you give appropriate credit to the original author(s) and the source, provide a link to the Creative Commons licence, and indicate if changes were made. The images or other third party material in this article are included in the article's Creative Commons licence, unless indicated otherwise in a credit line to the material. If material is not included in the article's Creative Commons licence and your intended use is not permitted by statutory regulation or exceeds the permitted use, you will need to obtain permission directly from the copyright holder. To view a copy of this licence, visit http://creativecommons.org/ licenses/by/4.0/. The Creative Commons Public Domain Dedication waiver (http://creativecommons.org/publicdomain/zero/1.0/) applies to the data made available in this article, unless otherwise stated in a credit line to the data.

\section{Abstract}

Background: The increased popularity of minimally invasive spinal surgery calls for a revision of guidance techniques to prevent injuries of nearby neural and vascular structures. Lipid content has previously been proposed as a distinguishing criterion for different bone tissues to provide guidance along the interface of cancellous and cortical bone. This study aims to investigate how fat is distributed throughout the spinal column to confirm or refute the suitability of lipid content for guidance purposes.

Results: Proton density fat fraction (PDFF) was assessed over all vertebral levels for six human cadavers between 53 and 92 years of age, based on fat and water MR images. According to their distance to the vertebra contour, the data points were grouped in five regions of interest (ROls): cortical bone $(-1 \mathrm{~mm}$ to $0 \mathrm{~mm}$ ), pre-cortical zone (PCZ) 1-3 (0-1 mm; 1-2 mm; 2-3 mm), and cancellous bone ( $\geq 3 \mathrm{~mm})$. For PCZ1 vs. PCZ2, a significant difference in mean PDFF of between $-7.59 \mathrm{pp}$ and $-4.39 \mathrm{pp}$ on average was found. For cortical bone vs. PCZ1, a significant difference in mean PDFF of between $-27.09 \mathrm{pp}$ and $-18.96 \mathrm{pp}$ on average was found.

Conclusion: A relationship between distance from the cortical bone boundary and lipid content could be established, paving the way for guidance techniques based on fat fraction detection for spinal surgery.

Keywords: Magnetic resonance imaging, Bone detection, Lipid content, Screw placement, Minimally invasive spine surgery

\section{Background}

Spinal fusion surgery is performed to treat fractures, reduce back pain or correct for spinal deformities due to scoliosis or degenerative spine conditions [1-3]. The vertebrae are typically fixed to each other with the use of metal rods anchored to the bone through pedicle screws. Pedicle screws run through the pedicle while their heads provide dedicated attachment points for the rods. However, the relatively soft tissue on the inside of the bone, the cancellous bone, is not strong enough for spine fixation. Therefore, pedicle screw fixation mainly relies on locations where the screw is in direct contact with the surrounding bone layer, the dense cortical bone [4]. Increasing the contact area between 
screws and cortical bone is thought to result in better fixation of the pedicle screws [5-7].

Spinal fusion is commonly carried out in a minimally invasive surgery (MIS) procedure as this shortens length of hospital stay and recovery $[8,9]$. MIS is performed through several small incisions, which necessitates guidance techniques for the surgeon to compensate for the limited visibility of the surgical site. The close proximity of neural and vascular structures and the inability to adjust the trajectory of the pedicle screw after insertion present an additional challenge to screw placement [10,11].

One possible approach to maximize the contact area between screws and cortical bone is to replace the conventionally used straight screws with a flexible anchoring device that runs along the interface of cancellous and cortical bone on a curved trajectory close to the outer edge of the vertebra. The need for reliable guidance is evident for such a device. Hence, it is crucial to determine reliable distinguishing criteria for cancellous and cortical bone that help to identify the correct trajectory. Burström et al. [12] have suggested lipid content as such a criterion and shown its potential to predict impending breaches in pedicle screw placement.

Lipids in the human body are commonly quantified using MRI. Several research groups have used this medical imaging technique to non-invasively measure fat fraction in the vertebral body to evaluate various clinical conditions such as osteoporosis [13, 14], cancer [15], and metabolic disorders such as obesity and diabetes [16, 17]. However, few studies focusing on the distribution of fat fraction within the vertebrae for distinction of cancellous and cortical bone are available so far [18].

This study, therefore, aims to investigate the fat fraction distribution throughout the spinal column of human cadavers and to identify a possible relationship between the distance from the cortical bone boundary and lipid content. The transition area between cancellous and cortical bone is of particular interest, given that a flexible anchoring device would be located in this area.

\section{Results}

\section{Extracted PDFF data}

For the cortical bone and the three PCZs, between 300 and 3500 individual PDFF values per vertebra and cadaver were extracted, respectively, depending on the vertebra size. The ROI of cancellous bone contained up to 20000 data points for the largest vertebrae.

Figure 1 displays the PDFF distributions obtained for the individual ROIs over all vertebral levels. The mean PDFF is displayed as a solid line. To each side, one standard deviation is highlighted in the corresponding color. The mean PDFFs and standard deviations over the whole spine are displayed to the right of each plot for the ROIs of the corresponding cadaver.

Figure 1 shows similar PDFF distributions for all cadavers, with the exception of Cadaver 5, which shows very low overall PDFF in comparison to the other cadavers.

The PDFF distributions show that natural variation among the individual vertebrae exists. This variation becomes especially apparent in Cadaver 3 (Fig. 1c). For the other cadavers, however, large deviations from the whole spine mean PDFF are rare and only occur for singular vertebrae (marked in Fig. 1 with downward pointing arrows). 


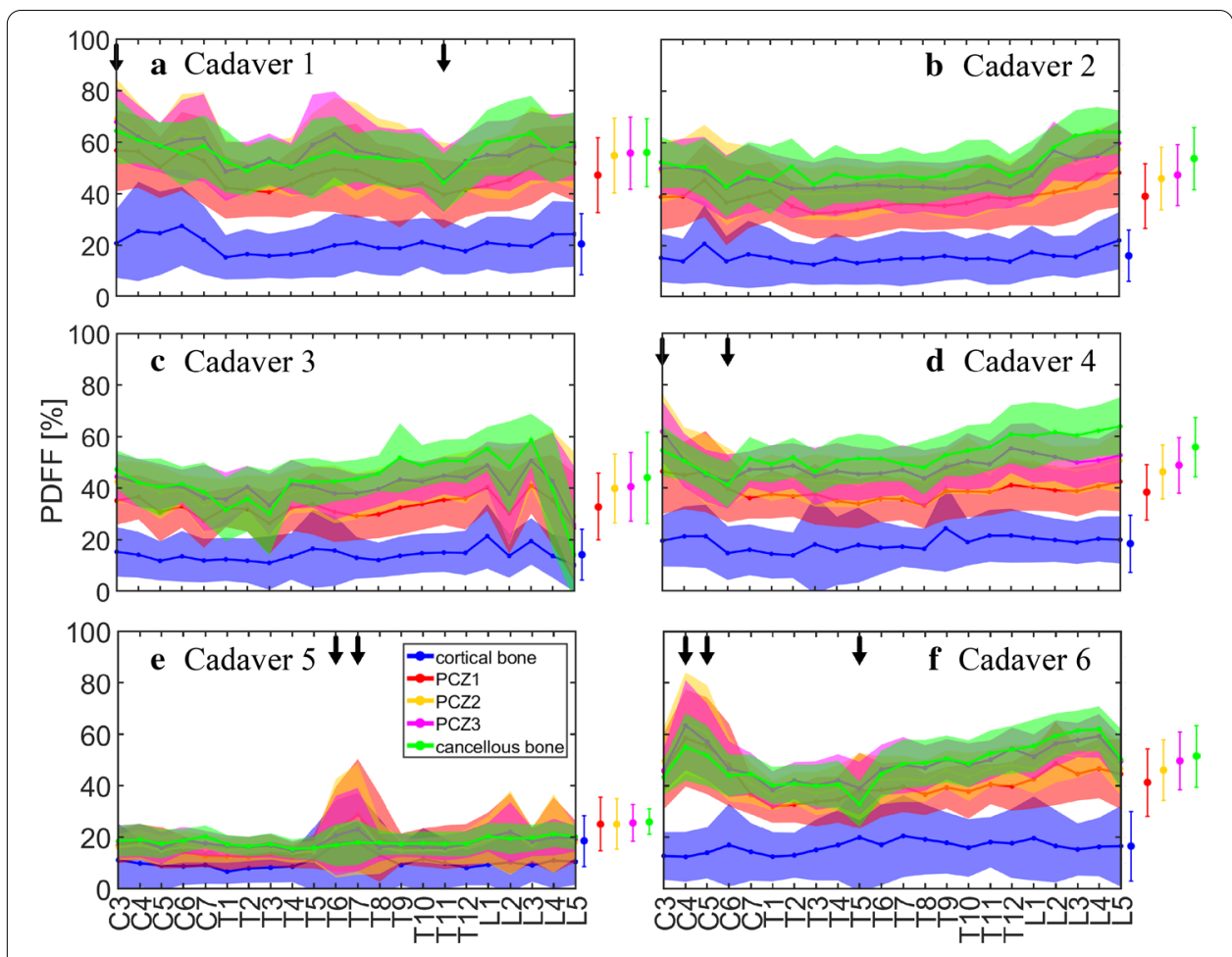

Fig. 1 PDFF distributions over all vertebral levels and whole spine mean PDFFs and standard deviations

All cadavers but Cadaver 5 exhibit a mean cortical bone PDFF of around 15-20\%. The curve of the cortical bone PDFF distribution is distinct from the distribution curves of the other ROIs. Mean PCZ1 PDFF lies between 30 and 50\%. For each of the cadavers, the PCZ1 PDFF distribution curve is partly below the distribution curves of the remaining ROIs. PCZ2, PCZ3, and cancellous bone exhibit elevated mean PDFF values, and their PDFF distribution curves overlap to a large extent.

In Cadaver 5, the mean cortical bone PDFF is around 10\%. The PDFF distribution curves for PCZ1, PCZ2, PCZ3 and cancellous bone overlap and exhibit mean values below $20 \%$.

\section{Results of the statistical analysis}

The box plots in Fig. 2 display the distribution of the mean differences in the PDFF for adjacent ROIs observed for the individual vertebrae of each cadaver. The plots show that mean differences behave similarly in all cadavers, with the exception of Cadaver 5 .

All cadavers but Cadaver 5 exhibit mean PDFF differences for PCZ3 vs. cancellous bone and for PCZ2 vs. PCZ3 whose plots are around or contain the value zero. The plots for PCZ1 vs. PCZ2 are below zero and display median values between -7.59 percentage points (pp) (Cadaver 1) and $-4.39 \mathrm{pp}$ (Cadaver 6). The plots for cortical bone vs. PCZ1 are also below zero and display median values between $-27.09 \mathrm{pp}$ (Cadaver 1 ) and -18.96 pp (Cadaver 3).

When used for guidance in spinal fusion surgery, fat fraction detection should enable the surgeon to detect the bone boundary and prevent breaching it. Assuming the surgeon to approach the outer layer (PCZ and cortical bone) from the inside of the bone, 


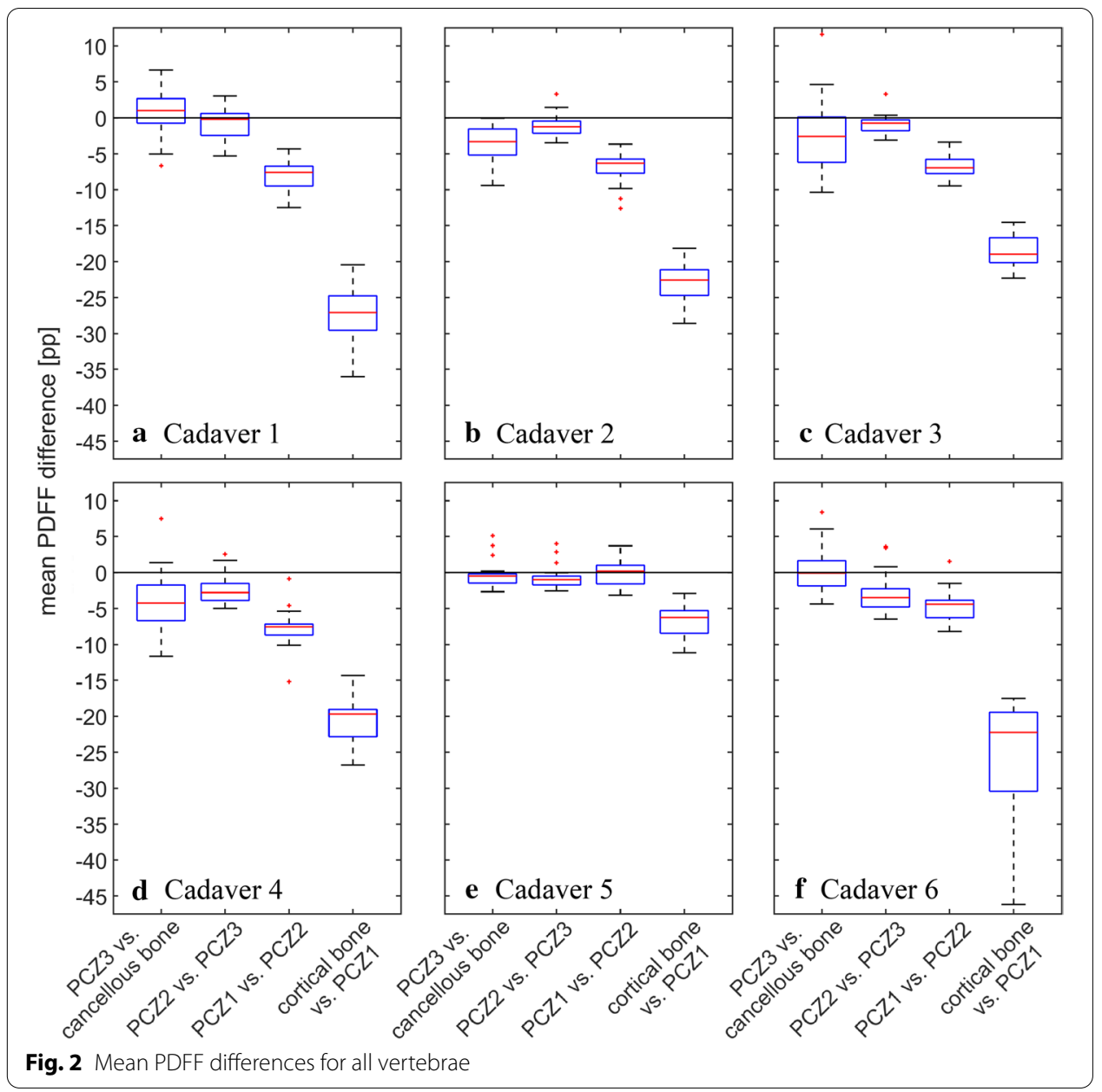

the first observed mean difference is at the interface of cancellous bone and PCZ3. After excluding the outliers, this difference is between $-11.64 \mathrm{pp}$ (Cadaver 4) and $+6.66 \mathrm{pp}$ (Cadaver 1) for the examined samples. For the transition from PCZ3 towards PCZ2, the mean PDFF difference varies from $-6.48 \mathrm{pp}$ (Cadaver 6) to $+3.02 \mathrm{pp}$ (Cadaver 1).

A difference in the mean PDFF of between -12.48 pp (Cadaver 1) and $-1.53 \mathrm{pp}$ (Cadaver 6) is found from PCZ2 towards PCZ1. The mean PDFF in the cortical bone changes by between $-46.19 \mathrm{pp}$ (Cadaver 6 ) and $-14.34 \mathrm{pp}$ (Cadaver 4 ) as compared to PCZ1.

For Cadaver 5, the plots of the mean PDFF differences for PCZ3 vs. cancellous bone, for PCZ2 vs. PCZ3 and for PCZ1 vs. PCZ2 all contain the value zero. The plot for cortical bone vs. PCZ1 is below zero and displays a median value of $-6.25 \mathrm{pp}$.

\section{Discussion}

In this study, we have investigated the distribution of PDFF in human cadaver vertebrae, with a particular focus on the transition zone between the cancellous and cortical regions of the bone (PCZ). As a flexible anchoring device would be affixed in the PCZ along the outer edge of the vertebra, the area around the spinal cord was considered irrelevant for the given application and was thus not part of the analysis. 
The cadavers included in this study had a mean age of 77.8 years and belonged to the patient cohort of older adults, which is the most common cohort for spinal fusion surgery. Patients in this cohort may suffer from back pain due to various clinical conditions including degenerative disk disease and spinal stenosis [2]. Measurements of PDFF in the cancellous bone from this ex-vivo study are in line with the results of previous in vivo research on similar patient cohorts $[13,19,20]$.

Similar PDFF distributions and mean PDFFs were observed for all cadavers, except for Cadaver 5. The study results show lower PDFF for Cadaver 5 compared to the rest of the cadavers studied. This subject was found to suffer from malignant neoplasm of the esophagus, which may be the cause of the low PDFF found across all spinal levels. Patients with active malignancy have a higher chance of perioperative complications and are less likely to be considered for spinal fusion surgery [21, 22]. The PDFF measurements for Cadaver 5 can therefore be assumed to be non-representative of vertebral body fat fraction in spinal surgery patients. The mean PDFF difference between cortical bone and PCZ1 found for this cadaver suggests that guidance based on fat fraction may still be possible for patients with active malignancies, but parameters would have to be assessed separately for these patients.

For the other cadavers, the observed PDFF distributions suggest that cortical bone can be distinguished from the remaining ROIs. Fat fraction seems to increase gradually from cortical bone through PCZ1 up to the three innermost ROIs (PCZ2, PCZ3, and cancellous bone). As the PDFF distributions of these three ROIs overlap, no distinction based on PDFF measurements seems possible here.

Statistical analysis confirms these findings: when examining the mean PDFF difference of PCZ3 vs. cancellous bone, no significance is found, as both positive and negative values are observed. Equally, for the mean PDFF difference of PCZ2 vs. PCZ3, the observed values do not consistently have the same sign, hence these zones are not considered significantly different.

When advancing from PCZ2 towards PCZ1, a first significant drop in the mean PDFF can be observed. For the examined samples, the average difference was between -7.59 pp (Fig. 2a) and -4.39 pp (Fig. 2f). Although consistently negative, the absolute values of the observed differences are small for some vertebrae, and it needs to be verified whether they can reliably serve for guidance in spinal fusion surgery.

When further advancing from PCZ1 towards cortical bone, another significant decrease in the mean PDFF is found. For the examined samples, the average difference was between -27.09 pp (Fig. 2a) and -18.96 pp (Fig. 2c). This decrease is in the same order of magnitude as the total mean cortical bone PDFF, and can, therefore, very likely be detected intra-operatively, and thus prevent the surgeon from traversing the cortical bone boundary.

For singular vertebrae, the PDFF curves reveal unusually large deviations from the whole spine mean. These vertebrae also show an altered anatomy on the PDFF MR images. Modic changes that come along with degenerative edema can lead to elevated grayscale values, which are associated with a high PDFF [23]. Another cause for large deviations from the whole spine mean are sclerotic lesions, which can, for instance, manifest as bone islands-intramedullary condensations of cortical bone which appear as areas with low signal intensity. 
In Cadaver 3, which reveals a particularly high variation in PDFF (Fig. 1c), several vertebrae exhibit dark spots. Possible explanations are an underlying malignancy with metastases that have destroyed the bone partially, or posterior vertebral scalloping that is a possible result of a variety of pathologies such as degenerative spine conditions, dural ectasia, and intraspinal tumors deforming the vertebra [24]. The influence of such anomalies on lipid content in the vertebrae needs to be researched, although the mean differences acquired in this study do not reveal substantial discrepancies for vertebrae with an altered anatomy.

Furthermore, it has been shown previously that the PDFF changes over the course of a lifetime [25]. This study focused on the most common patient cohort of older adults, and none of the examined cadavers belonged to the other patient cohort of adolescents suffering from spinal deformities [1]. A further study investigating fat fraction distribution in the vertebrae of this patient cohort is encouraged.

It could be argued that the vertebral fat content of cadavers may not represent the in vivo fat content due to postmortem changes. However, a study by Lamoureux et al. [26] showed that bovine and equine percentage of fat in bone marrow does not change within 30-60 days after necropsy, regardless of the storage condition. In an in vivo human study by de Boer et al. [27] fat content was assessed on tissue samples both before and after resection. Comparison of the measurements did not yield any significant differences.

\section{Limitations}

The model used for water-fat separation assumes that objects are scanned at body temperature. Although this model is relatively stable to variations in temperature, the calculated PDFF values might be slightly biased, as the cadavers examined in this study were not scanned at body temperature but at room temperature.

Selection of the vertebra contours was done by manually detecting high grayscale values on the MR image. Although the process was kept consistent for the entire dataset, it is prone to bias. Using CT images as ground truth for vertebra contour detection is recommended for future studies. Another possible approach to mitigate the bias is to increase the magnetic field strength from $1.5 \mathrm{~T}$ to $3 \mathrm{~T}$ for better separation of fat and water, thereby creating a higher contrast between cortical and cancellous bone on the MR images [28]. Image acquisition with an increased in-plane resolution could decrease the pixel size and thus increase the number of data points for each ROI.

The cortical bone ROI was grown automatically based on the detected vertebra contour and the assumption of a uniform cortical thickness of $1 \mathrm{~mm}$. Swamy et al.[29] have shown cortical bone thickness to vary between 1 and $3 \mathrm{~mm}$. However, cortical bone at a distance of more than $-1 \mathrm{~mm}$ from the vertebra contour is expected to show an equal or lower PDFF compared to the cortical bone ROI as defined in this study, creating an even larger mean difference between cortical bone and PCZ1.

Lastly, investigating PDFF distributions across additional slices and other 3D planes could provide further insights, especially concerning the PDFF distribution in the pedicle area, a crucial region for screw placement. 


\section{Conclusion}

This study investigated the fat fraction distribution, quantified through MRI, throughout the spinal column of six human cadavers. Lipid content was found to be related to the distance from the cortical bone boundary, and significant mean PDFF differences between cortical bone and the PCZ were found. Hence, in this study, fat fraction is found to be a valid criterion for distinction between the different bone tissues in vertebrae and has the potential to provide guidance in spinal fusion surgery.

\section{Methods}

In this research, six human cadavers (four females, two males) with an age range of 53-92 years (mean $=77.8$ years) were studied. One of the subjects examined (Cadaver 5) was known to have suffered from malignant neoplasm of the esophagus. All cadavers were donated for scientific research. Informed consent had been signed before death by the donors or after death by relatives, according to local guidelines and U.S. regulations. The study was conducted in compliance with ethical guidelines for human cadaver studies.

\section{Image acquisition}

MRI

The cadavers' entire spines were scanned on a 1.5 Tesla $(\mathrm{T})$ whole-body scanner (Ingenia, Philips Healthcare, Best, The Netherlands) in the prone position. The temperature of the cadavers was maintained at room temperature prior to scanning.

A three-dimensional (3D) six-echo spoiled gradient-echo sequence was used for chemical shift-encoding-based water-fat separation. The typical imaging parameters used in this study were: AP field of view $=220-310 \mathrm{~mm}$; FH field of view $=240-350$ $\mathrm{mm}$; slice thickness $=3 \mathrm{~mm}$; in-plane resolution $=1.2 \times 1.2 \mathrm{~mm}^{2}$; flip angle $=5^{\circ}$; TR $=9.9-15.87 \mathrm{~ms} ; \mathrm{TE} 1=1.41-1.43 \mathrm{~ms} ; \Delta \mathrm{TE}=1.2 \mathrm{~ms}$. Reconstruction with a voxel size of $(0.45-0.67) \times(0.45-0.67) \times 1.5 \mathrm{~mm}^{3}$ yielded $45-65$ sagittal slices per sequence.

To obtain whole spine coverage, the MR exam consisted of three 3D spoiled gradient-echo sequences placed on the cervical, thoracic and lumbar spine, respectively. Total scan time per cadaver was approximately 5-10 min.

\section{Determination of PDFF}

The scanner image reconstruction was used to separate the signals of water and fat using Philips DICOM viewer R3.0-SP04 (Philips Healthcare, Best, The Netherlands). The water-fat separation was based on a seven-peak water-fat spectral model [30].

Based on fat signal (F) and water signal (W), proton density fat fraction (PDFF) was calculated as:

$$
P D F F[\%]=\frac{F}{F+W} \cdot 100
$$




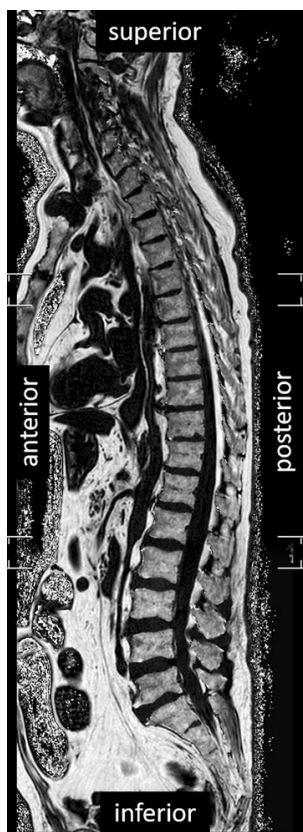

Fig. 3 Mid-sagittal PDFF MR image of the whole spine (Cadaver 6)

Figure 3 shows the visual representation of a PDFF MR image of the mid-sagittal slice of the whole spine.

\section{Image analysis}

For each cadaver, the three mid-sagittal slices (cervical, thoracic, lumbar) plus three respective adjacent slices on each side were retained for the analysis. The image analysis procedure was performed for vertebrae C3 through L5.

\section{ROI selection}

For each slice, regions of interest (ROIs) were selected on the MR image using the FIJI distribution of Image [31]. The contours of the single vertebrae were found based on grayscale value of the PDFF MR image and estimated vertebra shape, as shown in Fig. 4a. Anterior, inferior and superior walls were included in the analysis.

Burström et al.[12] have introduced the concept of a 3-mm-thick transition zone between cancellous and cortical bone, the so-called pre-cortical zone (PCZ). This idea was adopted in this work: pixels within a $3-\mathrm{mm}$ distance from the vertebra contour were assigned to one of three adjacent pre-cortical ROIs of $1 \mathrm{~mm}$ thickness each (PCZ1, PCZ2, PCZ3). An ROI within the vertebra at a distance of more than $3 \mathrm{~mm}$ to the contour was considered to contain the cancellous bone. An ROI of cortical bone was defined as the first $\mathrm{mm}(-1 \mathrm{~mm}$ to $0 \mathrm{~mm})$ outside the detected contour. The selected ROIs are shown in Fig. 4b. An overview of the ROIs can be found in Table 1.

\section{Data extraction}

Fat fraction distributions were calculated for the ROIs listed in Table 1 by calculating the PDFFs for all pixels included in the respective ROI using MATLAB R2019b (The 


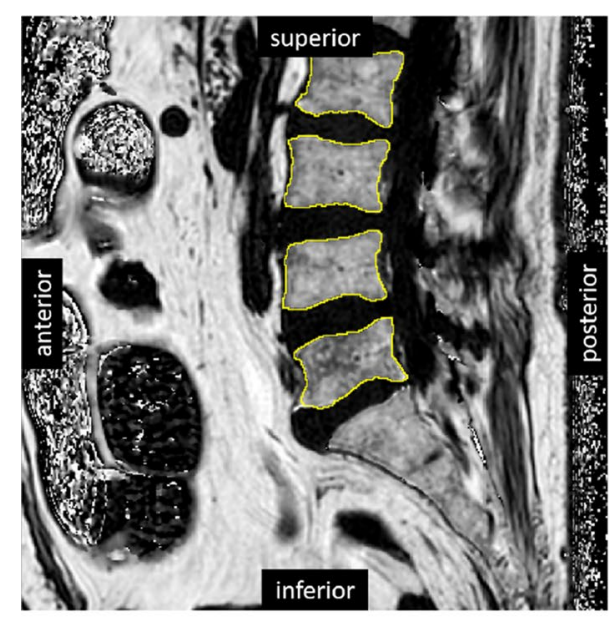

a

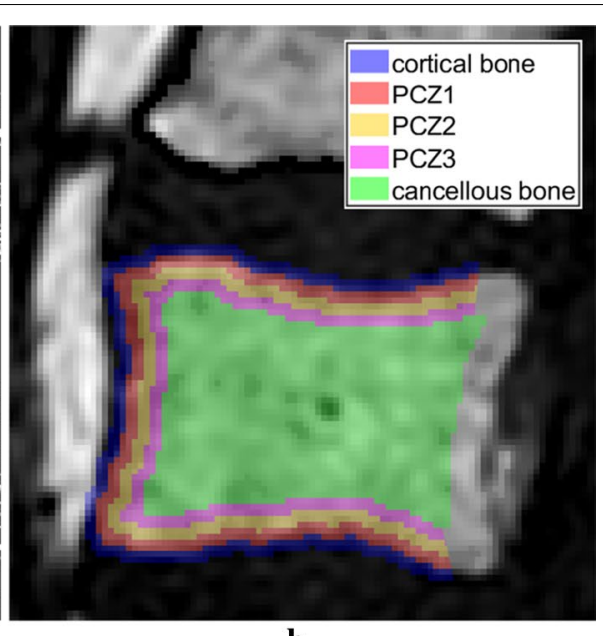

b

Fig. 4 ROI selection process: a Mid-sagittal PDFF MR image of the lumbar spine with detected vertebra contours b Definition of the anatomical ROls: cortical bone, pre-cortical zone (PCZ), and cancellous bone

Table 1 Overview of the defined ROIs

\begin{tabular}{lll}
\hline & Bone type & Distance from contour \\
\hline ROI0 & Cortical bone & $-1 \mathrm{~mm}$ to $0 \mathrm{~mm}$ \\
$\mathrm{ROI1}$ & $\mathrm{PCZ1}$ & $0 \mathrm{~mm}$ to $1 \mathrm{~mm}$ \\
$\mathrm{ROI} 2$ & $\mathrm{PCZ2}$ & $1 \mathrm{~mm}$ to $2 \mathrm{~mm}$ \\
$\mathrm{ROI3}$ & $\mathrm{PCZ3}$ & $2 \mathrm{~mm}$ to $3 \mathrm{~mm}$ \\
$\mathrm{ROI} 4$ & Cancellous bone & $\geq 3 \mathrm{~mm}$ \\
\hline
\end{tabular}

MathWorks Inc., Natick (MA), USA). For each vertebra within each cadaver, the data points gathered from the different slices were merged to yield one dataset per ROI.

\section{Statistical analysis}

To provide guidance in the context of spinal fusion surgery, individual variation in fat fraction is considered most important, so the data were analyzed separately for every vertebra in each of the cadavers.

Mean differences of the measured PDFFs were computed for the respective adjacent ROIs (cortical bone vs. PCZ1; PCZ1 vs. PCZ2; PCZ2 vs. PCZ3; PCZ3 vs. cancellous bone) as the difference of the outer ROI's mean PDFF value to the inner ROI's mean PDFF value. As reliable guidance is crucial for spinal surgery, a pair of adjacent ROIs was only considered significantly different if, after the exclusion of potential outliers, the mean differences observed for this pair consistently had the same sign for all vertebrae.

\section{Abbreviations}

3D: Three-dimensional; MIS: Minimally invasive surgery; PCZ: Pre-cortical zone; PDFF: Proton density fat fraction; pp: Percentage points; ROI: Region of interest.

\section{Acknowledgements}

The authors very much appreciate the valuable insights into the image acquisition process provided by Stefan Ruschke at the BMRR group of the Technical University of Munich. 


\section{Open Access}

This article is distributed under the terms of the Creative Commons Attribution 4.0 International License (http://creat ivecommons.org/licenses/by/4.0/), which permits unrestricted use, distribution, and reproduction in any medium, provided you give appropriate credit to the original author(s) and the source, provide a link to the Creative Commons license, and indicate if changes were made.

\section{Authors' contributions}

MSL and AS conceived the experiments and performed the experiments and the data analysis. AET and EE helped with the acquisition and interpretation of the MR images. MSL assessed the results and drafted the manuscript. AET, EE, BHWH and JD revised the manuscript. The study was supervised by BHWH and JD. All authors read and approved the final manuscript.

\section{Funding}

This study was supported by NWO-TTW 17553.

\section{Availability of data and materials}

The MRI datasets analyzed during the current study were collected by Philips following the required regulatoryapproval and are therefore not publicly available.The processed data is available at https://doi.org/10.4121/13089956.

\section{Ethics approval and consent to participate}

All cadavers were donated for scientific research. Informed consent had been signed before death by the donors or after death by relatives, according to local guidelines and U.S. regulations. The study was conducted in compliance with ethical guidelines for human cadaver studies.

\section{Consent for publication}

Not applicable.

\section{Competing interests}

The author affiliated with Philips Research (BHWH) has financial interests in the subject matter, materials, and equipment, in the sense that he is an employee of Philips. None of the other authors have any financial relationship or conflict of interests. Authors without conflicts of interest had full control of data analysis and information submitted for publication, and over all conclusions drawn in the manuscript.

\section{Author details}

${ }^{1}$ Department of Biomechanical Engineering, Delft University of Technology, Delft, The Netherlands. ${ }^{2}$ Department of In-Body Systems, Philips Research, Royal Philips, NV, Eindhoven, The Netherlands. ${ }^{3}$ Department of Clinical Neuroscience, Karolinska Institutet, Stockholm, Sweden. ${ }^{4}$ Department of Neurosurgery, Karolinska University Hospital, Stockholm, Sweden.

Received: 15 October 2020 Accepted: 28 December 2020

Published online: 07 January 2021

\section{References}

1. Weinstein SL, Dolan LA, Cheng JC, Danielsson A, Morcuende JA. Adolescent idiopathic scoliosis. Lancet. 2008;371(9623):1527-37.

2. Deyo RA, Gray DT, Kreuter W, Mirza S, Martin BI. United states trends in lumbar fusion surgery for degenerative conditions. Spine. 2005;30(12):1441-5.

3. Dick W, Kluger P, Magerl F, Woersdörfer O, Zäch G. A new device for internal fixation of thoracolumbar and lumbar spine fractures: the 'fixateur interne.' Spinal Cord. 1985;23(4):225-32.

4. Eswaran SK, Gupta A, Adams MF, Keaveny TM. Cortical and trabecular load sharing in the human vertebral body. Journal of Bone and Mineral Research. 2006;21(2):307-14.

5. Luther N, lorgulescu JB, Geannette C, Gebhard H, Saleh T, Tsiouris AJ, Härtl R. Comparison of navigated versus nonnavigated pedicle screw placement in 260 patients and 1434 screws. Journal of Spinal Disorders and Techniques. 2015;28(5):298-303.

6. Rajasekaran S, Bhushan M, Aiyer S, Kanna R, Shetty AP. Accuracy of pedicle screw insertion by airo ${ }^{\circledR}$ intraoperative ct in complex spinal deformity assessed by a new classification based on technical complexity of screw insertion. European Spine Journal. 2018;27(9):2339-47.

7. Solitro GF, Whitlock K, Amirouche F, Mehta Al, McDonnell A. Currently adopted criteria for pedicle screw diameter selection. International journal of spine surgery. 2019;13(2):132-45.

8. Oppenheimer JH, DeCastro I, McDonnell DE. Minimally invasive spine technology and minimally invasive spine surgery: a historical review. Neurosurgical Focus. 2009;27(3):9.

9. Goldstein CL, Macwan K, Sundararajan K, Rampersaud YR. Perioperative outcomes and adverse events of minimally invasive versus open posterior lumbar fusion: meta-analysis and systematic review. Journal of Neurosurgery: Spine. 2016;24(3):416-27.

10. Kosmopoulos V, Schizas C. Pedicle screw placement accuracy: a meta-analysis. Spine. 2007;32(3):111-20.

11. Staartjes VE, Klukowska AM, Schröder ML. Pedicle screw revision in robot-guided, navigated, and freehand thoracolumbar instrumentation: a systematic review and meta-analysis. World Neurosurgery. 2018;116:433-43.

12. Burström G, Swamy A, Spliethoff JW, Reich C, Babic D, Hendriks BH, Skulason H, Persson O, Elmi Terander A, Edström E. Diffuse reflectance spectroscopy accurately identifies the pre-cortical zone to avoid impending pedicle screw breach in spinal fixation surgery. Biomedical Optics Express. 2019;10(11):5905-20. 
13. Yeung DK, Griffith JF, Antonio GE, Lee FK, Woo J, Leung PC. Osteoporosis is associated with increased marrow fat content and decreased marrow fat unsaturation: a proton mr spectroscopy study. Journal of Magnetic Resonance Imaging. 2005;22(2):279-85.

14. Li X, Kuo D, Schafer AL, Porzig A, LinkTM, Black D, Schwartz AV. Quantification of vertebral bone marrow fat content using 3 tesla mr spectroscopy: reproducibility, vertebral variation, and applications in osteoporosis. Journal of Magnetic Resonance Imaging. 2011;33(4):974-9.

15. Schraml C, Schmid M, Gatidis S, Schmidt H, la Fougèe C, Nikolaou K, Schwenzer NF. Multiparametric analysis of bone marrow in cancer patients using simultaneous pet/mr imaging: Correlation of fat fraction, diffusivity, metabolic activity, and anthropometric data. Journal of Magnetic Resonance Imaging. 2015;42(4):1048-56.

16. Bredella MA, Torriani M, Ghomi RH, Thomas BJ, Brick DJ, Gerweck AV, Rosen CJ, Klibanski A, Miller KK. Vertebral bone marrow fat is positively associated with visceral fat and inversely associated with igf-1 in obese women. Obesity. 2011;19(1):49-53.

17. Baum T, Yap SP, Karampinos DC, Nardo L, Kuo D, Burghardt AJ, Masharani UB, Schwartz AV, Li X, LinkTM. Does vertebral bone marrow fat content correlate with abdominal adipose tissue, lumbar spine bone mineral density, and blood biomarkers in women with type 2 diabetes mellitus? Journal of Magnetic Resonance Imaging. 2012;35(1):117-24.

18. Swamy A, Burström G, Spliethoff JW, Babic D, Ruschke S, Racadio JM, Edström E, Elmi-Terander A, Dankelman J, Hendriks BH. Validation of diffuse reflectance spectroscopy with magnetic resonance imaging for accurate vertebral bone fat fraction quantification. Biomedical optics express. 2019;10(8):4316-28.

19. Kühn J-P, Hernando D, Meffert PJ, Reeder S, Hosten N, Laqua R, Steveling A, Ender S, Schröder H, Pillich D-T. Protondensity fat fraction and simultaneous $\mathrm{r}^{*}$ estimation as an mri tool for assessment of osteoporosis. European radiology. 2013;23(12):3432-9.

20. Schwartz AV, Sigurdsson S, Hue TF, Lang TF, Harris TB, Rosen CJ, Vittinghoff E, Siggeirsdottir K, Sigurdsson G, Oskarsdottir $\mathrm{D}$, et al. Vertebral bone marrow fat associated with lower trabecular bmd and prevalent vertebral fracture in older adults. The Journal of Clinical Endocrinology \& Metabolism. 2013;98(6):2294-300.

21. Copeland G, Jones D, Walters M. Possum: a scoring system for surgical audit. British Journal of Surgery. 1991;78(3):355-60.

22. Ribeiro, K.d.C.B., Kowalski, L.P. . Apache ii, possum, and asa scores and the risk of perioperative complications in patients with oral or oropharyngeal cancer. Archives of Otolaryngology-Head \& Neck Surgery. 2003;129(7):739-45.

23. Fields AJ, Battié MC, Herzog RJ, Jarvik JG, Krug R, Link TM, Lotz JC, O'Neill CW, Sharma A, et al. Measuring and reporting of vertebral endplate bone marrow lesions as seen on mri (modic changes): recommendations from the issls degenerative spinal phenotypes group. European Spine Journal. 2019;1-9

24. Wakely SL. The posterior vertebral scalloping sign. Radiology. 2006;239(2):607-9.

25. Baum T, Rohrmeier A, Syväri J, Diefenbach MN, Franz D, Dieckmeyer M, Scharr A, Hauner H, Ruschke S, Kirschke $J \mathrm{~S}$, et al. Anatomical variation of age-related changes in vertebral bone marrow composition using chemical shift encoding-based water-fat magnetic resonance imaging. Frontiers in Endocrinology. 2018;9:141.

26. Lamoureux JL, Fitzgerald SD, Church MK, Agnew DW. The effect of environmental storage conditions on bone marrow fat determination in three species. Journal of Veterinary Diagnostic Investigation. 2011;23(2):312-5.

27. de Boer LL, Hendriks BH, Van Duijnhoven F, Peeters-Baas M-JTV, Van de Vijver K, Loo CE, Jóźwiak K, Sterenborg HJ, Ruers TJ. Using drs during breast conserving surgery: identifying robust optical parameters and influence of interpatient variation. Biomedical optics express. 2016;7(12):5188-200.

28. Soher BJ, Dale BM, Merkle EM. A review of mr physics: 3t versus 1.5t. Magnetic resonance imaging clinics of North America. 2007;15(3):277-90.

29. Swamy A, Burström G, Spliethoff JW, Babic D, Reich C, Groen J, Edström E, Terander AE, Racadio JM, Dankelman J, et al. Diffuse reflectance spectroscopy, a potential optical sensing technology for the detection of cortical breaches during spinal screw placement. Journal of biomedical optics. 2019;24(1):017002.

30. Ren J, Dimitrov I, Sherry AD, Malloy CR. Composition of adipose tissue and marrow fat in humans by $1 \mathrm{~h} \mathrm{nmr}$ at 7 tesla. Journal of lipid research. 2008;49(9):2055-62.

31. Schindelin J, Arganda-Carreras I, Frise E, Kaynig V, Longair M, Pietzsch T, Preibisch S, Rueden C, Saalfeld S, Schmid B, et al. Fiji: an open-source platform for biological-image analysis. Nature methods. 2012;9(7):676-82.

\section{Publisher's Note}

Springer Nature remains neutral with regard to jurisdictional claims in published maps and institutional affiliations.

Ready to submit your research? Choose BMC and benefit from:

- fast, convenient online submission

- thorough peer review by experienced researchers in your field

- rapid publication on acceptance

- support for research data, including large and complex data types

- gold Open Access which fosters wider collaboration and increased citations

- maximum visibility for your research: over $100 \mathrm{M}$ website views per year

At BMC, research is always in progress.

Learn more biomedcentral.com/submissions 